\title{
High Performance Liquid Chromatography (HPLC) Fingerprinting, Mineral Composition and In Vitro Antioxidant Activity of Methanol Leaf Extract of Synsepalum dulcificum (Sapotaceae)
}

\author{
Tajudeen Olabisi Obafemi ${ }^{1,2} *$, Afolabi Clement Akinmoladun ${ }^{1}$, Mary Tolulope Olaleye ${ }^{1}$, Amos Onasanya ${ }^{2}$, \\ Kayode Charles Komolafe ${ }^{3}$, John Adeolu Falode ${ }^{3}$, Aline Augusti Boligon ${ }^{4}$, Margareth Linde Athayde ${ }^{4}$ \\ ${ }^{1}$ Phytomedicine, Drug Metabolism and Toxicology Unit, Department of Biochemistry, The Federal University of Technology, Akure, Nigeria. \\ ${ }^{2}$ Department of Chemical Sciences, Afe Babalola University, Ado - Ekiti, Nigeria. \\ ${ }^{3}$ Department of Biochemistry, Federal University Oye-Ekiti, Nigeria. \\ ${ }^{4}$ Phytochemical Research Laboratory, Department of Industrial Pharmacy, Federal University of Santa Maria, Santa Maria, Brazil.
}

\begin{tabular}{|c|c|}
\hline ARTICLE INFO & ABSTRACT \\
\hline Article history: & This study was carried out to identify the phytochemicals and in vitro antioxidant activity of methanol leaf \\
\hline Received on: 03/06/2016 & extract of Synsepalum dulcificum (MSD). Standard protocols were used to evaluate the total phenols, total \\
\hline Accepted on: 11/10/2016 & flavonoids and total antioxidants content of the extract. Nitric oxide (NO), hydroxyl radical $(\mathrm{OH}), \mathrm{ABTS}^{-+}$and \\
\hline Available online: $30 / 11 / 2017$ & 2,2-diphenyl -1-picrylhydrazyl (DPPH) radicals scavenging activity, inhibition of lipid peroxidation and the \\
\hline $\begin{array}{l}\text { Key words: } \\
\text { Flavonoids, reducing power, } \\
\text { trolox, free radical, } \\
\text { biochemical. }\end{array}$ & $\begin{array}{l}\text { Liquid Chromatography (HPLC) was used to confirm the presence of polyphenols and carotenoids. Results } \\
\text { showed the presence of flavonoids, saponins, terpenoids and cardiac glycosides in the extract. Among others, } \\
\text { appreciable levels of potassium, calcium, sodium and magnesium were detected in the extract. The IC } \mathrm{C}_{50} \text { of the } \\
\text { extract for DPPH, } \mathrm{NO}, \mathrm{OH}^{-} \text {, and ABTS }{ }^{+} \text {radicals scavenging assays were } 139.45 \mu \mathrm{g} / \mathrm{ml}, 119.17 \mu \mathrm{g} / \mathrm{ml}, 147.65 \\
\mu \mathrm{g} / \mathrm{ml} \text {, and } 135.83 \mu \mathrm{g} / \mathrm{ml}^{2} \text { respectively. It could be inferred that MSD showed appreciable in vitro antioxidant } \\
\text { activity and could be useful in preventing and ameliorating diseases in which free radicals are implicated. }\end{array}$ \\
\hline
\end{tabular}

\section{INTRODUCTION}

In recent times medicinal plants have occupied a unique position among the treatment modalities of a wide variety of diseases. This might not be unconnected with the presence of biologically active molecules in such plants especially molecules that have been proven to have therapeutic potentials in several

\footnotetext{
* Corresponding Author

Obafemi T. Olabisi, Afe Babalola University PMB 5454, Ado - Ekiti, Nigeria . Phone: +234 8038059340; Email: oobafemi @ abuad.edu.ng
}

experimental disease models. Such molecules include flavonoids, tannins, steroids, terpenoids, saponins etc. These molecules have been shown to be responsible for the medicinal value of the plants in which they are found, including their antioxidant activity (Yildrim et al., 2001).

The antioxidant activity of a compound has been attributed to various mechanisms viz: prevention of chain initiation, binding of transition metal ion catalysts, decomposition of peroxides, prevention of continued hydrogen abstraction, reductive capacity and radical scavenging ability (Saumya and Mahaboob, 2011). 
Moreover, The World Health Organization (WHO) stated that more than $80 \%$ of the population in developing countries use herbal and other traditional medicines to treat their common ailments (WHO, 1998). Free radicals are highly reactive chemical species regularly produced in the human system by normal biological reactions and also by various exogenous factors. Some of the radicals include superoxide $\mathrm{O}_{2}{ }^{-}$, nitric oxide (NO), peroxyl (ROO), and hydroxyl ( $\left.\mathrm{OH}^{-}\right)$(Maritim et al., 2003). These ROS play an important role in degenerative or pathological processes, such as aging, cancers, coronary heart diseases, Alzheimer's disease, neurodegenerative disorders, atherosclerosis, cataracts and inflammations (Huang et al., 2005). Living organisms have endogenous antioxidant defense systems that protect against oxidative damage by removal or repair of damaged molecules (Sun et al., 1998). The term 'antioxidant' refers to the activity of numerous vitamins, minerals and phytochemicals which provide protection against the damage caused by ROS (Khilfi et al., 2006). Antioxidants interfere with the oxidative processes by scavenging free radicals, chelating free catalytic metals and by acting as electron donor (Gulcin et al., 2005). More often than not, the endogenous antioxidant mechanisms may be overwhelmed in several diseased conditions thereby necessitating the supplementation of antioxidant levels through intake of dietary and plant derived antioxidants (Terao et al., 1994). Plant-based antioxidants are now preferred to the synthetic ones because of safety concerns (Grice, 1986; Wichi, 1988). These factors have inspired the widespread screening of plants for possible medicinal and antioxidant properties, the isolation and characterization of diverse phytochemicals and the development and utilization of antioxidants of natural origin (Jayaprakasha et al., 2001; Gulcin et al., 2002). It is believed that the phytochemical composition and the in-vitro antioxidant activity of a plant might give a clue to its therapeutic potential.

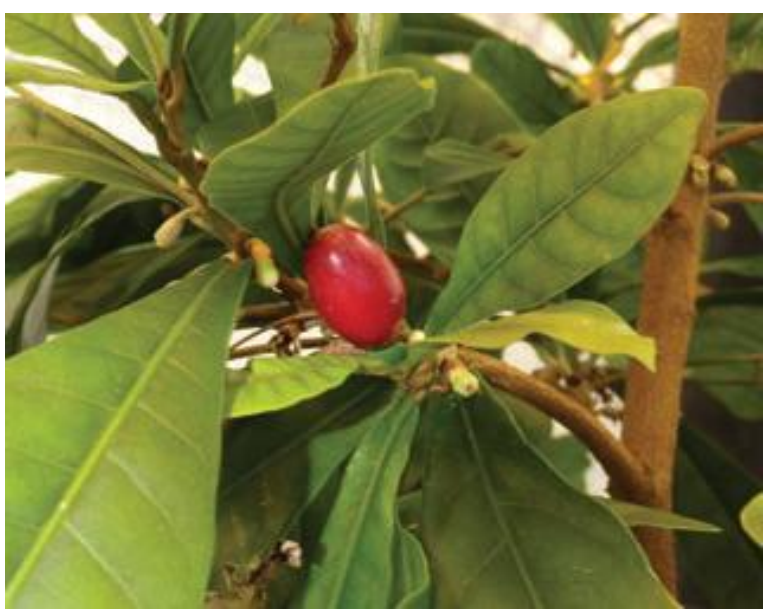

Fig. 1: Synsepalum dulcificum leaves (George and Diejun, 2011).

The miracle fruit shrub, Synsepalum dulificum Daniell (Sapotaceae) is indigenous to tropical West Africa. The fruit berries of the plant have unusual taste modifying properties of allowing sour substances to taste amazingly sweet after the inside of the mouth has been thoroughly exposed to the fruit's mucilaginous pulp (Brouwer et al., 1968). Miracle fruit has been studied to improve insulin resistance induced by fructose-rich chow in rats (Chen et al., 2006). Researchers also reported that the skin contributed $43.96 \%$ of free phenolic compounds with $15.91 \%$ of freeze-dried solids due to its high phenolic content. They also observed that the free flavonoid content in the skin was tremendously higher than that in the seed and pulp and that the skin contributed about $52 \%$ of total flavonoid and $15.91 \%$ of dried solids (George and Diejun, 2011). However to the best of our knowledge the antioxidant activity of the methanol extract of Synsepalum dulcificum leaves has not been evaluated, hence this study.

\section{MATERIALS AND METHODS}

\section{Chemicals}

Acetonitrile, formic acid, gallic acid, chlorogenic acid, ellagic acid and caffeic acid were purchased from Merck (Darmstadt, Germany). Quercetin, quercitrin, isoquercitrin, rutin, catechin, epicatechin and kaempferol, DPPH (2,2-diphenyl-1picrylhydrazyl) radical, gallic acid, ascorbic acid, quercetin and Folin-Ciocalteau reagent were obtained from Sigma Chemical Co. (St. Louis, MO, USA). All other chemicals and reagents used were of analytical grade.

\section{Plant material and extraction}

S. dulcificum leaves were collected from a farmland in Iseyin, Oyo-state in South-Western Nigeria. The leaves were identified and a voucher number- UIH-22457 was obtained for the leaf at Botany Department University of Ibadan, Nigeria. The leaves were air-dried for three weeks and pulverized. $700 \mathrm{~g}$ of the pulverized sample was extracted in $80 \%$ methanol by maceration for 72 hours. The methanol extract was concentrated in a rotary evaporator and lyophilized. A total yield of the extract $(98.7 \mathrm{~g}$, $14.1 \%$ ) was obtained and preserved for further use.

\section{Quantification of compounds by HPLC-DAD}

Reverse phase chromatographic analyses were carried out under gradient conditions using $\mathrm{C}_{18}$ column (4.6 mm x 250 $\mathrm{mm})$ packed with $5 \mu \mathrm{m}$ diameter particles. The mobile phase was water containing $1 \%$ formic acid (A) and acetonitrile (B), and the composition gradient was: $13 \%$ of $\mathrm{B}$ until $10 \mathrm{~min}$ and changed to obtain $20 \%, 30 \%, 50 \%, 60 \%, 70 \%, 20 \%$ and $10 \%$ B at 20, 30, 40, 50, 60, 70 and $80 \mathrm{~min}$, respectively (Boligon et al., 2012) with slight modifications. Synsepalum dulcificum (leaves) methanolic extractwas analyzed dissolved in ethanol at a concentration of 20 $\mathrm{mg} / \mathrm{mL}$. The presence of eleven antioxidants compounds was investigated, namely, gallic acid, chlorogenic acid, caffeic acid, ellagic acid, catechin, epicatechin, quercetin, quercitrin, isoquercitrin, rutin and kaempferol. Identification of these compounds was performed by comparing their retention time and UV absorption spectrum with those of the commercial standards. The flow rate was $0.7 \mathrm{ml} / \mathrm{min}$, injection volume $50 \mu \mathrm{l}$ and the 
wavelength were $254 \mathrm{~nm}$ for gallic acid, $280 \mathrm{~nm}$ for catechin and epicatechin, $327 \mathrm{~nm}$ for caffeic, ellagic and chlorogenic acids, and $366 \mathrm{~nm}$ for quercetin, isoquercitrin, quercitrin, rutin and kaempferol. All the samples and mobile phase were filtered through $0.45 \mu \mathrm{m}$ membrane filter (Millipore) and then degassed by ultrasonic bath prior to use. Stock solutions of standards references were prepared in the HPLC mobile phase at a concentration range of $0.030-0.250 \mathrm{mg} / \mathrm{ml}$ for kaempferol, quercetin, isoquercitrin, quercitrin, catechin, epicatechin and rutin; and $0.030-0.250$ $\mathrm{mg} / \mathrm{ml}$ for gallic, caffeic, ellagic and chlorogenic acids. The chromatography peaks were confirmed by comparing its retention time with those of reference standards and by DAD spectra (200 to $400 \mathrm{~nm})$. All chromatography operations were carried out at ambient temperature and in triplicate. The limit of detection (LOD) and limit of quantification (LOQ) were calculated based on the standard deviation of the responses and the slope using three independent analytical curves. LOD and LOQ were calculated as 3.3 and $10 \sigma / \mathrm{S}$, respectively, where $\sigma$ is the standard deviation of the response and $\mathrm{S}$ is the slope of the calibration curve (Boligon et al., 2013).

\section{DPPH (1, 1, diphenyl 2-picryl hydrazyl) assay}

The antioxidant activity by DPPH assay was assessed according to Molyneux method (Molyneux, 2004). To $1 \mathrm{ml}$ of various concentration of the extract $1 \mathrm{ml}$ of DPPH $0.1 \mathrm{mM}$ was added in a test tube. Tannic acid was used as the standard for comparison. After incubation for $30 \mathrm{mins}$ in dark at room temperature, absorbance was recorded at $517 \mathrm{~nm}$. The percent DPPH radical scavenging was calculated with the equation:

$\%$ DPPH radical scavenging $=[$ (Absorbance control Absorbance sample)/ Absorbance control] $\times 100$.

\section{ABTS radical scavenging activity}

A TEAC assay was conducted based on the method of Ramos et al., (1999). The ABTS aqueous solution (7 mM) was oxidized with potassium peroxodisulfate $(2.45 \mathrm{mM})$ for 16 hours in the dark at room temperature. The $\mathrm{ABTS}^{-+}$solution was diluted with $95 \%$ ethanol to an absorbance of $0.75 \pm 0.05$ at $734 \mathrm{~nm}$. An aliquot $(20 \mu \mathrm{L})$ of each sample $(125 \mu \mathrm{g} / \mathrm{mL})$ was mixed with 180 $\mu \mathrm{L} \mathrm{ABTS}++$ solution and the absorbance was read at $734 \mathrm{~nm}$ after 1 min. Trolox was used as a reference standard. The percent $\mathrm{ABTS}^{*+}$ radical scavenging was calculated with the equation:

$\%$ ABTS $^{*+}$ radical scavenging $=[($ Absorbance control -

Absorbance sample)/ Absorbance control] $\times 100$.

\section{Nitric oxide scavenging activity}

The nitric oxide scavenging activity was evaluated according to the modified method of Sreejayan and Rao (1997). Various concentrations of extract was prepared. Sodium nitroprusside $(2.5 \mathrm{~mL}, 10 \mathrm{mM})$ in phosphate buffered saline (PBS) was added to $0.5 \mathrm{~mL}$ different concentrations of extracts. The reaction mixture was incubated at $25^{\circ} \mathrm{C}$ for $150 \mathrm{~min}$. After incubation, $0.5 \mathrm{~mL}$ aliquot was removed and $0.5 \mathrm{~mL}$ of Griess reagent: (1\% (w/v) sulfanilamide, $2 \%(\mathrm{v} / \mathrm{v}) \mathrm{H}_{3} \mathrm{PO}_{4}$ and $0.1 \%(\mathrm{w} / \mathrm{v})$ naphthylethylene diamine hydrochloride) was added. The absorbance was measured at $546 \mathrm{~nm}$. Ascorbic acid was used as reference standard and was treated the same way as that of fractions. Sodium nitroprusside in PBS (2 mL) was used as control. The nitric oxide radicals scavenging activity of the extracts and ascorbic acid was calculated according to the following equation:

Percentage of inhibition $=\left[\left(\mathrm{A}_{0}-\mathrm{A}_{1}\right) / \mathrm{A}_{0}\right] \times 100$, where $\mathrm{A}_{0}$ is the absorbance of sodium nitroprusside in PBS and A1 is the absorbance in the presence of the fractions and ascorbic acid.

\section{Iron chelating ability assay}

The in vitro $\mathrm{Fe}^{2+}$ chelating ability of plant extract was assayed according to the method of Minnoti and Aust, 1987 with slight modification (Minnoti and Aust, 1987). Briefly, $900 \mu \mathrm{l}$ of aqueous $\mathrm{FeSO}_{4}(500 \mu \mathrm{M})$ and $150 \mu \mathrm{l}$ of extract were incubated for $5 \mathrm{~min}$ at room temperature, $78 \mu \mathrm{l}$ of 1,10 - phenanthroline $(0.25 \%$ ,w/v, aqueous) was added. The absorbance of the orange colour solution was read at $510 \mathrm{~nm}$ with a spectrophotometer. The principle of the assay is based on disruption of o-phenanthroline $\mathrm{Fe}^{2+}$ complex in the presence of chelating agent. The in vitro of $\mathrm{Fe} 2+$ chelating ability of the sample was calculated by using the following formula:

Chelating ability $(\%)=\left(\mathrm{A}_{\text {control }}-\mathrm{A}_{\text {sample }}\right) / \mathrm{A}_{\text {control }} \mathrm{x} 100$. Where;

$\mathrm{A}_{\text {control }}=$ The absorbance of the control (reaction mixture in the absence of sample)( $\mathrm{FeSO}_{4}$ alone).

$\mathrm{A}_{\text {sample }}=$ The absorbance of the reaction mixture (sample, $\mathrm{FeSO}_{4}$ and 1,10-phenanthroline)

\section{Reductive potential}

Reducing power of the extracts were measured by the direct reduction of $\left.\mathrm{Fe}^{3+(} \mathrm{CN}^{-}\right)^{6}$ to $\left.\mathrm{Fe}^{2+(} \mathrm{CN}^{-}\right)_{6}$ and was determined by absorbance measurement of the formation of the Perl's Prussian Blue complex following the addition of excess $\mathrm{Fe}^{3+}$ (Oyaizu, 1986), as described previously (Gulcin 2006b). Different concentrations of extracts in $0.5 \mathrm{~mL}$ of distilled water were mixed with $1.25 \mathrm{~mL}$ of $0.2 \mathrm{M}, \mathrm{pH} 6.6$ sodium phosphate buffer and $1.25 \mathrm{~mL}$ of potassium ferricyanide $\left[\mathrm{K}_{3} \mathrm{Fe}(\mathrm{CN})_{6}\right](1 \%)$ the mixture was incubated at $50{ }^{\circ} \mathrm{C}$ for $20 \mathrm{~min}$. After $20 \mathrm{~min}$ incubation, the reaction mixture was acidified with $1.25 \mathrm{~mL}$ of trichloroacetic acid (10\%). Finally, 0.5 $\mathrm{mL}$ of $\mathrm{FeCl}_{3}(0.1 \%)$ was added to this solution and the absorbance was measured at $700 \mathrm{~nm}$ in a spectrophotometer. Increased absorbance of the reaction mixture indicates greater reduction capability (Gulcin, 2006a).

\section{Hydroxyl radical scavenging activity}

The hydroxyl radical $(\mathrm{OH})$ scavenging activity was measured by the method of Jin et al. (1996). The hydroxyl radical was generated in a mixture of $1.0 \mathrm{~mL}$ of $0.75 \mathrm{mM} \mathrm{1,10-}$ phenanthroline, $2.0 \mathrm{~mL}$ of $0.2 \mathrm{M}$ sodium phosphate buffer $(\mathrm{pH}$ 7.4), $1.0 \mathrm{~mL}$ of $0.75 \mathrm{mM}$ FeSO 4 and $1.0 \mathrm{~mL}$ of $\mathrm{H}_{2} \mathrm{O}_{2}(0.01 \%$, v/v). After addition of $1.0 \mathrm{Ml}$ sample solution, the mixture was incubated at $37^{\circ} \mathrm{C}$ for $30 \mathrm{~min}$. Then, the absorbance of the mixture at $536 \mathrm{~nm}$ was measured. Deionized water and VC were used as 
the blank and positive control respectively. The scavenging activity on ${ }^{-} \mathrm{OH}$ was calculated by the following equation:

Scavenging activity $(\%)=\left(\mathrm{Abs}_{\text {sample }}-\mathrm{Abs}_{\text {blank }}\right) /\left(\mathrm{Abs} 0-\mathrm{Abs}_{\text {blank }}\right)$ $* 100$

where $\mathrm{Abs} 0$ is the absorbance of the deionized water instead of $\mathrm{H}_{2} \mathrm{O}_{2}$ and sample in the assay system.

\section{Inhibition of lipid peroxidation assay}

In vitro inhibition of lipid peroxidation was estimated according to the method of Ruberto and Baratta (2000). In this assay, egg yolk homogenate served as lipid rich medium, and $\mathrm{FeSO}_{4}$ acts as initiator of lipid peroxidation .Briefly, 50 $\mu \mathrm{l}$ of plant extract was mixed with $0.25 \mathrm{ml} 10 \%$ egg yolk .This was followed by the addition of $10 \mu \mathrm{I} \mathrm{FeSO}_{4}(0.07 \mathrm{M}$, aqueous $)$. The mixture was incubated at room temperature for $30 \mathrm{~min}$. This was followed by the addition of $0.75 \mathrm{ml}$ of glacial acetic $\operatorname{acid}(5 \%, \mathrm{v} / \mathrm{v}$ aqueous) and $0.75 \mathrm{ml}$ of thiobarbituric acid $0.8 \%$ in Sodium dodecylsulphate (SDS) $1.1 \%$. The mixture was incubated in a boiling water bath $\left(90^{\circ} \mathrm{C}\right)$ for $60 \mathrm{~min}$, cooled and centrifuged at 3000rpm. One milliliter $(1 \mathrm{ml})$ of the pink colour supernant was read at $532 \mathrm{~nm}$ on a spectrophotometer.

In vitro inhibition of lipid peroxidation $=[$ (Acontol Asample)/Acontrol] X 100

\section{Determination of total phenolic content}

The total phenolic content of the extract was determined according to the method described elsewhere (Hung et al., 2001). In this assay, the phenolic group present in plant extract interacts with Folin - Ciocalteau in alkaline medium using $\mathrm{Na}_{2} \mathrm{CO}_{3}$ solution giving a blue colour, which has maximum absorption at $685 \mathrm{~nm}$ and correlates with total phenolic content. $0.1 \mathrm{ml}$ of aqueous extract of the plant of different concentrations $(2-10 \%)$ was rapidly mixed with $0.1 \mathrm{ml}$ of Folin Ciocalteu reagent ,followed by the addition of $0.3 \mathrm{ml}$ sodium carbonate $(15 \%, \mathrm{w} / \mathrm{v})$ solution. The mixture was incubated in the dark for 30mins. The absorbance of the blue colour was read at $760 \mathrm{~nm}$ after $30 \mathrm{mins}$ on a spectrophotometer. The total phenolic content was extrapolated from a standard curve using tannic acid (graded doses, 50 $250 \mathrm{ug} / \mathrm{ml}$ ) as a standard phenol.

\section{Determination of total flavonoid}

Total flavonoid of the leaf extract was determined using the method described by Kumaran and Karunakaran, (2007) with slight modification. Briefly, $0.5 \mathrm{ml}$ of extract solution $(1 \mathrm{mg} / \mathrm{ml})$ and standard (quercetin) at different concentrations were taken in test tubes. $3.0 \mathrm{ml}$ of methanol followed by $0.1 \mathrm{ml}$ of $10 \%$ aluminum chloride solution was added into the test tubes. Two hundred $\mathrm{ml}$ of $1 \mathrm{M}$ potassium acetate solution was added to the mixtures in the test tubes. Furthermore, each reaction test tube was then immediately diluted with $2.8 \mathrm{ml}$ of distilled water and mixed to incubate for $30 \mathrm{~min}$ at room temperature to complete reaction. The absorbance of pink colored solution was noted at $415 \mathrm{~nm}$ using a spectrophotometer against blank methanol. TFC of the extract was expressed as quercetin equivalents (QE) after calculation using the following equation: $\mathrm{C}=(\mathrm{cV}) / \mathrm{m}$, where, $\mathrm{C}$ =total flavonoid contents, $\mathrm{mg} / \mathrm{g}$ plant extract in $\mathrm{QE}, \mathrm{c}=$ concentration of quercetin obtained from calibration curve $(\mathrm{mg} / \mathrm{ml}), \mathrm{V}=$ the volume of the sample solution $(\mathrm{ml}), \mathrm{m}=$ weight of the sample $(\mathrm{g})$. All tests were conducted in triplicate.

\section{Determination of mineral composition}

Copper, zinc, magnesium, lead, manganese, calcium and iron content of MSD were analyzed using atomic absorption spectrophotometer (Buck 210 VGD), while sodium and potassium content were analyzed using flame photometer (Gulfex medical and scientific, England).

\section{Statistical analysis}

All statistical analyses were performed using Microsoft excel package 2013 version. Results are expressed as mean \pm standard deviation. Independent sample t-test was used for data analysis. Linear regression analysis was used to calculate the $\mathrm{IC}_{50}$ values.

\section{DISCUSSION}

Before the advent of modern medicine herbs and herbal products were the mainstay of treatments around the world. The phytochemicals present in commonly consumed plant foods are normally non-toxic and have the potential for preventing chronic diseases. The plant extracts encompass high concentration of flavonoids and phenolic compounds. As potent antioxidants, flavonoids are especially important for protection against human diseases. The multiple properties of these phytochemicals have made them more attractive, as they can modulate various aspects of diseases like lipid peroxidation involved in atherogenesis, thrombosis, carcinogenesis, hepatotoxicity and a variety of disease conditions (Tiwari, 2001). Table 1 shows the phytochemical composition of the methanol extract of $S$. dulcificum leaves. Flavonoids, saponins, terpenoids and cardiac glycosides were present in the extract. Our result as presented in table 2 also showed that the total phenols and total flavonoids were estimated to be $58.67 \mathrm{mg} / \mathrm{g}$ TAE and $13.01 \mathrm{mg} / \mathrm{g}$ QE respectively.

Table 1: Phytochemical screening of methanol leaf extract of Synsepalum dulcificum.

\begin{tabular}{cc}
\hline Phytochemical & Result \\
\hline Saponins & $+\mathrm{ve}$ \\
Tannins & $-\mathrm{ve}$ \\
Flavonoids & $+\mathrm{ve}$ \\
Alkaloids & $-\mathrm{ve}$ \\
Terpenoids & $+\mathrm{ve}$ \\
Anthraquinones & $-\mathrm{ve}$ \\
Cardiac glycosides & $+\mathrm{ve}$ \\
Steroids & $-\mathrm{ve}$ \\
\hline
\end{tabular}

Table 2: Total phenol and total flavonoids content of methanol leaf extract of Synsepalum dulcificum.

Total phenol $\quad 58.67 \mathrm{mg} / \mathrm{gTAE}$

Total flavonoids $\quad 13.01 \mathrm{mg} / \mathrm{gQE}$ 
The evaluation of the antioxidant activity of medicinal plants has become a key component of the processes employed in unraveling the therapeutic potentials of such plants. Researchers opined that no single assay accurately reflects the mechanism of action of all radical sources or all antioxidants in a complex system (Prior et al., 2005) and that two or more methods should be employed in order to evaluate the total antioxidant activity (Ilhami et al., 2005) due to various oxidative processes.

DPPH radical scavenging activity is usually used to estimate the in-vitro antioxidant activity of natural compounds or plant extracts (Philips et al., 2010). As shown in figure 3 The DPPH scavenging activity of methanolic extract of Synsepalum dulcificum leaves compared favorably with tannic acid at all the concentrations tested. At the highest concentration- $400 \mu \mathrm{g} / \mathrm{ml}$ the extract showed $91.84 \%$ inhibition while the standard antioxidant showed $93.53 \%$ inhibition of DPPH radical. The result also showed that the extract exhibited a dose-dependent inhibition of DPPH radical.

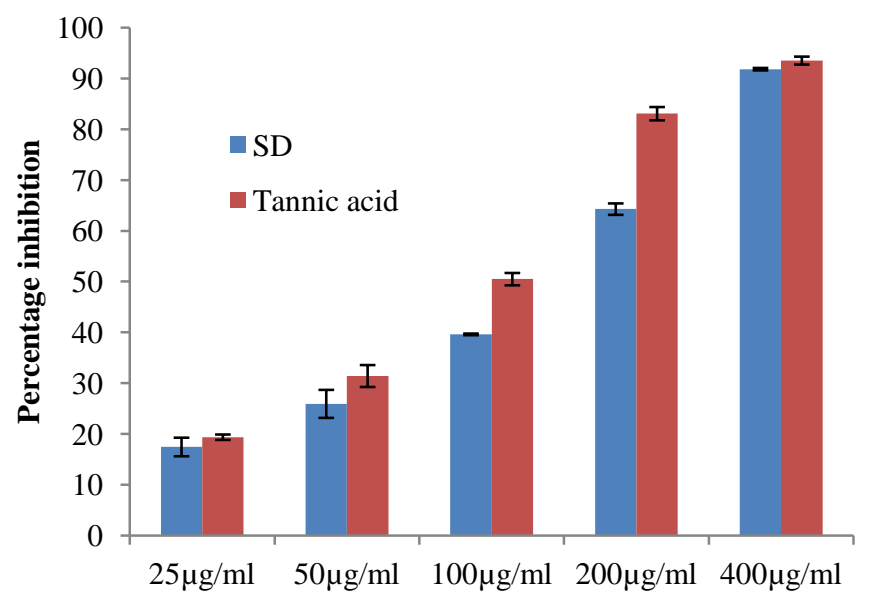

\section{Concentration}

Fig. 3: Percentage DPPH radical inhibition of methanol leaf extract of SD.

$\mathrm{ABTS}^{+\bullet}$ is a blue chromophore produced by the reaction between ABTS and potassium persulfate and in the presence of the plant extract or trolox. Preformed cation radical gets reduced and the remaining radical cation concentration after reaction with antioxidant compound was then quantified (Johnston, 2006). In the present study as presented in figure 4, methanol extract of SD leaves showed a remarkable $\mathrm{ABTS}^{+\bullet}$ scavenging activity when compared with trolox. At $200 \mu \mathrm{g} / \mathrm{ml}$ and $400 \mu \mathrm{g} / \mathrm{ml}$ the extract showed $85.29 \%$ and $87.99 \%$ scavenging activity respectively against the ABTS radical while trolox showed $70.57 \%$ and $83.18 \%$ scavenging activity respectively at the same doses.

Nitric oxide is a free radical produced in mammalian cells, involved in the regulation of various physiological process including neurotransmission, vascular homeostasis, antimicrobial and antitumor activities. However, excess production of $\mathrm{NO}$ is associated with several diseases. It would be interesting to develop potent and selective inhibitors of NO for potential therapeutic use
(Hepsibha, 2010). Figure5 shows that SD showed a dosedependent increase in nitric oxide scavenging activity. At $400 \mu \mathrm{g} / \mathrm{ml}$ which was the highest concentration tested the extract showed $69.42 \%$ scavenging activity while ascorbic acid which was used as standard showed $88.27 \%$ nitric oxide scavenging activity.

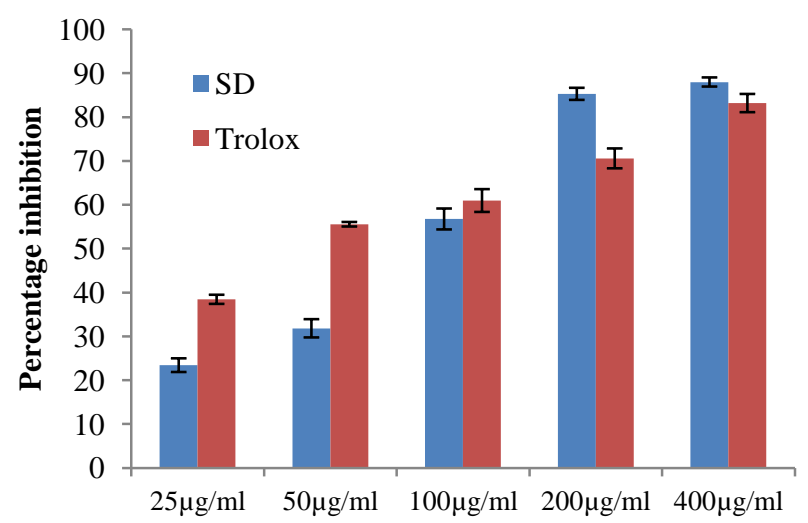

Concentration

Fig. 4: Percentage ABTS radical inhibition of methanol leaf extract of SD.

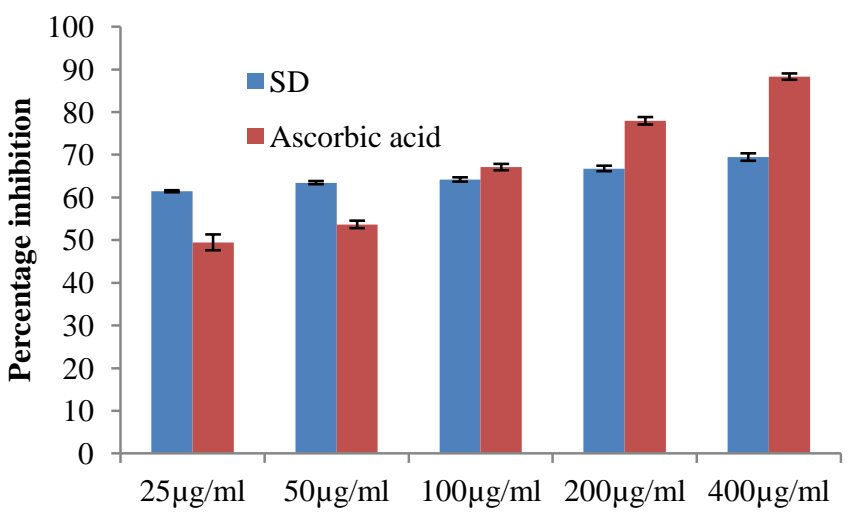

Concentration

Fig. 5: Percentage nitric oxide scavenging activity of methanol leaf extract of SD.

Chelating agents form $\sigma$-bonds with a metals and are effective as secondary antioxidants because they reduce the redox potential, thereby stabilizing the oxidized form of the metal ion (Kumaran and Karunakaran, 2006). Figure 6 shows the percentage iron-chelating activity of our extract. The result shows that though the EDTA which was used as standard showed a better ironchelating ability than the extract at all the doses tested, the extract still showed appreciable activity in this regard. At $400 \mu \mathrm{g} / \mathrm{ml}$ the extract and standard showed $48.86 \%$ and $60.52 \%$ iron-chelating activity respectively.

The reducing capacity of a compound may serve as a significant indicator of its potential antioxidant activity. Most antioxidants and pharmacologically therapeutic agents used in the treatment of oxidative stress related diseases have been shown to 
have strong reducing power (Amin and Razieh, 2007). The result in figure 7 shows that the methanol extract of Synsepalum dulcificum leaves showed an appreciable reducing power when compared to quercetin which was used as the standard antioxidant. At $400 \mu \mathrm{g} / \mathrm{ml}$ the extract and standard showed absorbance values of 1.21 and 1.80 respectively.

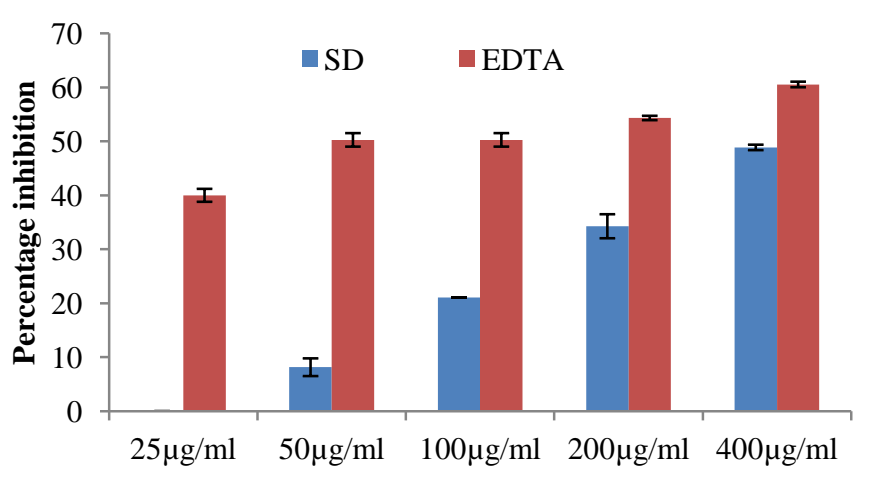

\section{Concentration}

Fig. 6: Percentage iron chelating activity of methanol leaf extract of SD.

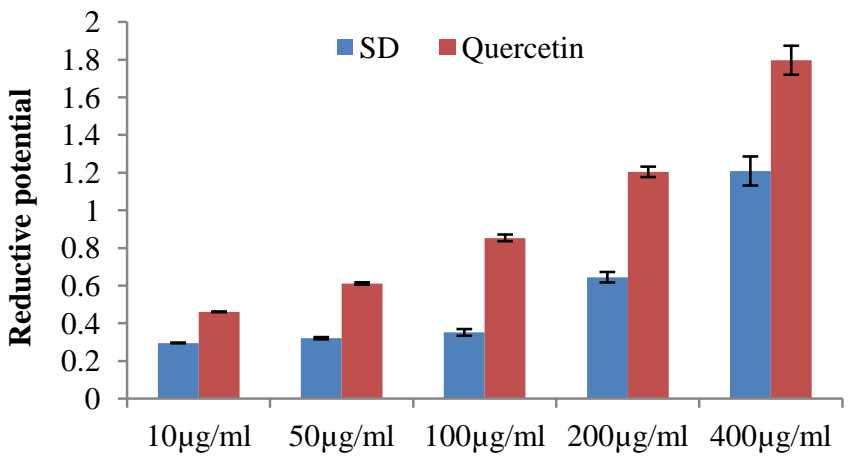

Concentration

Fig. 7: Reductive potential of methanol leaf extract of SD.

This implies that the extract compared favourably with the standard in the reductive potential assay. The reducing capacity is generally associated with the presence of reductones and the antioxidant action of reductones is based on the breaking of the free radical chain by donating a hydrogen atom (Gordon and Hudson, 1990). The result indicated that the marked reducing power of the extract might be due to the presence of polyphenols which may act in a similar fashion as reductones.

The hydroxyl radical is an extremely reactive free radical formed in biological systems and has been implicated as a highly damaging species in free radical pathology, capable of damaging almost every molecule formed in living cells (Hochestein and Attalah, 1988). Hydroxyl radicals are also known to initiate peroxidation of lipid membranes (Halliwell, 1991). The radical has the capacity to form adducts with nucleotides in DNA and cause strand breakage which contributes to carcinogenesis, mutagenesis and cytotoxicity (Thirunavukkarasu et al., 2011). Our result in figure8 shows that methanol extract of SD leaves has a high hydroxyl radical scavenging activity which compared favourably with mannitol in a dose-dependent manner. At the highest concentration tested the extract and standard showed percentage hydroxyl radical scavenging activity of $79.86 \%$ and $80.56 \%$ respectively.

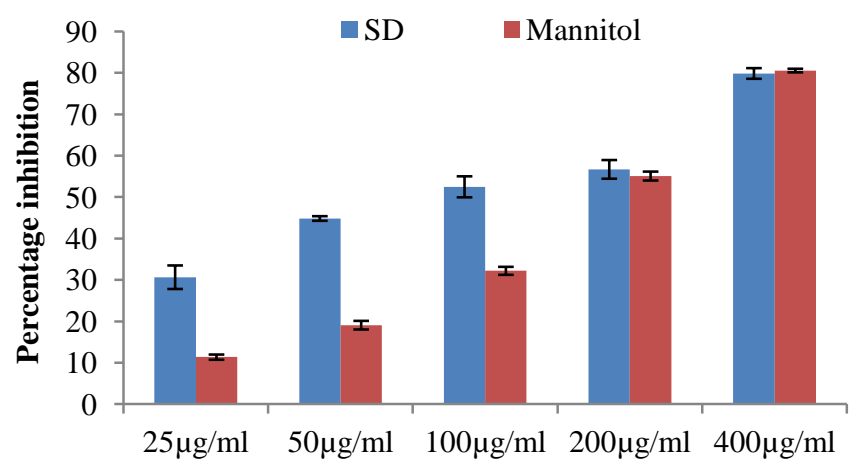

\section{Concentration}

Fig. 8: Percentage hydroxyl radical scavenging activity of methanol leaf extract of SD.

Lipid peroxidation in biological systems has long been thought to be a toxicological phenomenon that can lead to various pathological consequences (Hochestein and Attalah, 1988). Lipid peroxidation is caused by the generation of free radicals from a variety of sources including organic hydroperoxides, redox cycling compounds and iron-containing compounds. The TBARS assay has been used to measure the degree of lipid peroxidation. TBA reacts specifically with malondialdehyde (MDA), a secondary product of lipid peroxidation to give a red chromogen, which may then be determined spectrophotometrically (Giri et al., 2010). In this study, it was observed that methanol extract of SD leaves showed a moderate inhibition of lipid peroxidation. Our result as presented in figure9 shows that the extract has a dose dependent inhibition of lipid peroxidation with the highest concentration tested $-400 \mu \mathrm{g} / \mathrm{ml}$ showing a percentage inhibition of $48.79 \%$ while ascorbic acid had a percentage inhibition of $74.65 \%$ at the same concentration.

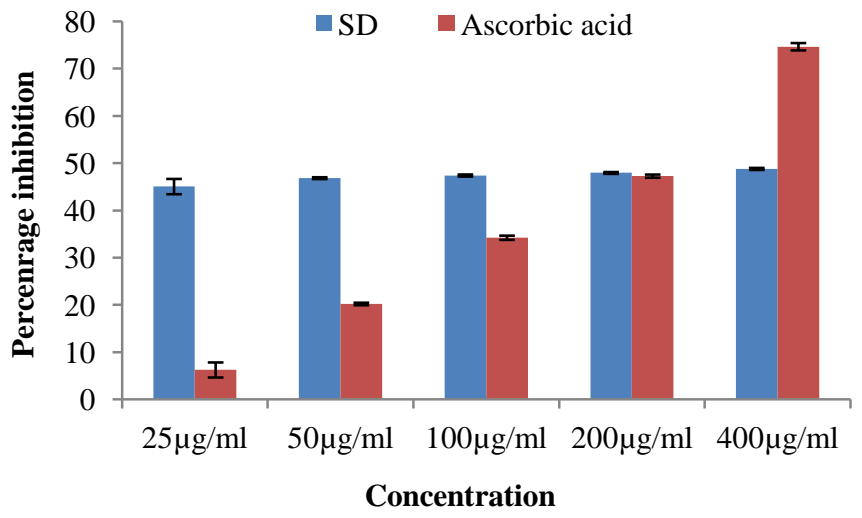

Fig. 9: Percentage inhibition of lipid peroxidation activity of methanol leaf extract of SD. 
The $\mathrm{IC}_{50}$ of the extract for DPPH, NO, $\mathrm{OH}^{-}$, and $\mathrm{ABTS}^{+}$ radicals scavenging assays were $139.45 \mu \mathrm{g} / \mathrm{ml}, 119.17 \mu \mathrm{g} / \mathrm{ml}$, $147.65 \mu \mathrm{g} / \mathrm{ml}$, and $135.83 \mu \mathrm{g} / \mathrm{ml}$ respectively, while its $\mathrm{IC}_{50}$ for iron chelation and inhibition of lipid peroxidation were 345.03 $\mu \mathrm{g} / \mathrm{ml}$ and $164.19 \mu \mathrm{g} / \mathrm{ml}$ respectively

HPLC/DAD fingerprint should be considered to evaluate the quality of herbal medicines all over the world considering the fact that multiple constituents are present in herbal medicines and its product (Coppen et al., 1983). Our results as shown in tables 3 and 4 show that the extract has a high level of polyphenols in the order flavonoids $(85.96 \mathrm{mg} / \mathrm{g} / 8.58 \%)>$ phenolic acids $(63.5 \mathrm{mg} / \mathrm{g}$ / $6.33 \%)>$ tannins $(23.87 \mathrm{mg} / \mathrm{g} / 2.38 \%)$.

Table 3: Composition of methanol leaf extract of Synsepalum dulcificum.

\begin{tabular}{lcccc}
\hline Compounds & \multicolumn{2}{c}{ Synsepalum dulcificum } & LOD & LOQ \\
\cline { 2 - 5 } & $\mathbf{m g} / \mathbf{g}$ & $\boldsymbol{\%}$ & $\boldsymbol{\mu g} / \mathbf{m L}$ & $\boldsymbol{\mu} \mathbf{g} / \mathbf{m L}$ \\
\hline Gallic acid & $6.18 \pm 0.03^{\mathrm{a}}$ & 0.61 & 0.024 & 0.079 \\
Catechin & $5.95 \pm 0.01^{\mathrm{a}}$ & 0.59 & 0.015 & 0.049 \\
Chlorogenic acid & $20.93 \pm 0.01^{\mathrm{b}}$ & 2.09 & 0.007 & 0.023 \\
Caffeic acid & $14.82 \pm 0.03^{\mathrm{c}}$ & 1.48 & 0.035 & 0.115 \\
Ellagic acid & $21.57 \pm 0.01^{\mathrm{b}}$ & 2.15 & 0.028 & 0.091 \\
Epicatechin & $17.92 \pm 0.01^{\mathrm{d}}$ & 1.79 & 0.021 & 0.070 \\
Rutin & $30.65 \pm 0.03^{\mathrm{e}}$ & 3.06 & 0.042 & 0.138 \\
Isoquercitrin & $15.03 \pm 0.02^{\mathrm{c}}$ & 1.50 & 0.010 & 0.032 \\
Quercitrin & $12.76 \pm 0.01^{\mathrm{f}}$ & 1.27 & 0.019 & 0.063 \\
Quercetin & $21.90 \pm 0.01^{\mathrm{b}}$ & 2.19 & 0.026 & 0.084 \\
Kaempferol & $5.62 \pm 0.01^{\mathrm{a}}$ & 0.56 & 0.013 & 0.042 \\
\hline
\end{tabular}

Results are expressed as mean \pm standard deviations (SD) of three determinations. Averages followed by different letters differ by Tukey test at $\mathrm{p}$ $<0.01$.

Table 4: Carotenoids compositions ofmethanol leaf extract Synsepalum dulcificum.

\begin{tabular}{cc}
\hline Carotenoids & $\begin{array}{c}\text { S. dulcificum } \\
\mathbf{~ m g} / \mathbf{g}\end{array}$ \\
\hline Tocopherol & $2.06 \pm 0.01^{\mathrm{a}}$ \\
$\beta$-Carotene & $2.93 \pm 0.04^{\mathrm{a}}$ \\
Lycopene & $0.57 \pm 0.01^{\mathrm{a}}$ \\
\hline
\end{tabular}

Results are expressed as mean \pm standard deviations (SD) of three determinations. Averages followed by different letters differ by Tukey test at $\mathrm{p}$ $<0.01$.

Among the flavonoids rutin was the most abundant followed by quercetin, isoquercitrin, quercitrin and kaempferol in that order. Ellagic acid is the most abundant among the phenolic acids present in the extract followed by chlorogenic acid, caffeic acid, and gallic acid in that order. For tannins our result also shows that the extract contains a higher level of epicatechin than catechin. The presence of carotenoids was also established in the extract. Figure 2 shows the chromatogram indicating the peaks of the polyphenols that were detected in the extract. HPLC is a sensitive, accurate and specific method for the separation and identification of phenolic acids, flavonoid glycosides and aglycones in plants. (Praven, 2012; Ana et al., 2009). Moreover, many sources indicate good correlations between phenolics content and antioxidant capacity evaluated by different techniques, including HPLC (Benzie and Strain, 1999; Brand-Williams et al., 1995), and Praven, (2012) asserted that plants exhibited medicinal properties due to the presence of flavonoids in it. We therefore opine that the presence of these plant polyphenols may contribute in part to the significant antioxidant properties of MSD as observed in this study.

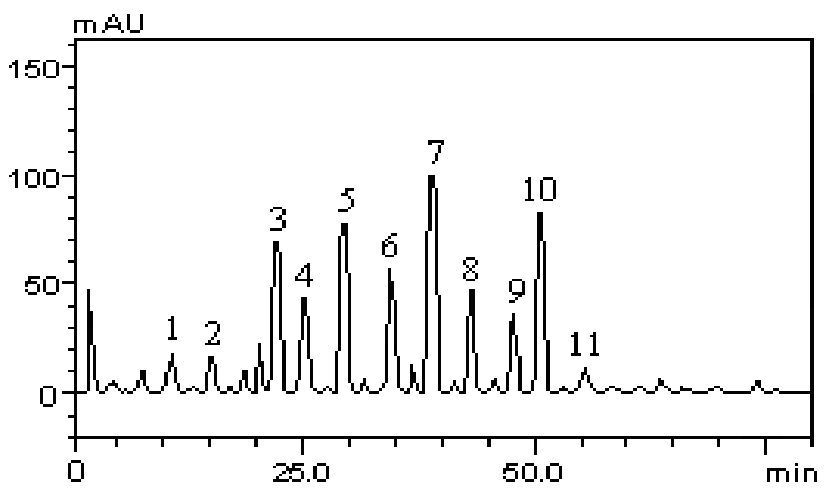

Fig. 2: HPLC chromatogram of methanol leaf extract of Synsepalum dulcificum. Representative high performance liquid chromatography profile of Synsepalum dulcificumat 327nm. Gallic acid (peak 1), catechin (peak 2), chlorogenic acid (peak 3), caffeic acid (peak 4), ellagic acid (peak 5), epicatechin (peak 6), rutin (peak 7), isoquercitrin (peak 8), quercitrin (peak 9), quercetin (peak 10) and kaempferol (peak 11).

The medicinal value of the plants lies in the chemical substances that produce a definite physiological action on human body (Hill, 1952). The distribution of minerals in common medicinal plants has important application for the health of people in addition to the basic need of developing countries.

Therefore there is need to evaluate the local herbs for mineral and nutrient composition, so as to determine their potential as indigenous source of medicine (Rahila et al., 1994). Our result in table 5 shows that presence of some micro and macro elements. Potassium, calcium, magnesium and sodium are present in appreciable amounts while lead, a heavy metal is present in trace quantity.

Table 5: Mineral composition of methanol leaf extract of Synsepalum dulcificum.

$\begin{array}{cc}\text { Metals } & \mathrm{mg} / 100 \mathrm{~g} \\ \text { Copper } & 1.10 \\ \text { Zinc } & 4.16 \\ \text { Magnessium } & 291.0 \\ \text { Lead } & 0.01 \\ \text { Manganese } & 8.70 \\ \text { Calcium } & 830.0 \\ \text { Iron } & 26.30 \\ \text { Sodium } & 102.0 \\ \text { Potassium } & 1850.0\end{array}$

\section{CONCLUSION}

From our study it could be safely concluded that the methanolic extract of Synsepalum dulcificum leaves has appreciable in vitro antioxidant activity and mineral content. This is a clear pointer to the possibility of the plant having potential health benefits especially in diseases in which oxidants have been established as the culprit. To confirm this possibility however, more research needs to be carried out using models of the diseases in question. 
Financial support and sponsorship: None.

Conflict of Interests: There are no conflicts of interest.

\section{REFERENCES}

Amin A., Razieh Y. Antioxidant and free radical scavenging potential of Achillea santolina extracts. Food Chem, 2007; 104: 21-29.

Ana P, Franz B, Željan M, Ana M, Biljana N, Nikola K.Identification and Quantification of Flavonoids and Phenolic Acids in Burr Parsley (Caucalis platycarpos L.), Using High-Performance Liquid Chromatography with Diode Array Detection and Electrospray Ionization Mass SpectrometryMolecules 2009; 14: 2466-2490.

Benzie FF, Strain JJ. Ferric reducing/antioxidant power assay: Direct measure of total antioxidant activity of biological fluids and modified version for simultaneous measurement of total antioxidant power and ascorbic acid concentration. Method Enzymol, 1999; 299:15-27.

Boligon AA, Brum TF, Frolhich JK, Froeder ALF, Athayde ML. HPLC/DAD profile and determination of total phenolics, flavonoids, tannins and alkaloids contents of Scutia buxifolia Reissek stem bark. Res $J$ Phytochem. 2012; 6: 84-91.

Boligon AA, Kubiça TF, Mario DN, Brum TF, Piana M, Weiblen R, Lovato L, Alves SH, Santos RCV, Alves CFS, Athayde ML. Antimicrobial and antiviral activity-guided fractionation from Scutia buxifolia Reissek extracts. Acta Physiol Plant. 2013; 35: 2229-2239.

Brand-Williams et al., 1995)2. Brand-Williams W, Cuvelier ME, Berset C. Use of a free radical method to evaluate antioxidant activity. LWT-Food Sci Technol 1995; 28:25-30.

Brouwer JN, Van DerWel H, Francke A, Henning GJ. Miraculin, the sweetness-inducing protein from miracle fruit. Nature, 1968; 220: 371-3.

Chen CC, Liu IM, Cheng JT. Improvement of insulin resistance by miracle fruit (Synsepalum dulcificum) in fructose-rich chow-fed rats. Phytotherapy Res, 2006; 20: 987-92.

Coppen PP, Allen JC, Hamilton RJ 1983. Rancidity in foods. Applied Science Publishers, New York, USA.

Giri L, Andola HC, Purohit VK, Rawat MSM, Rawal RS, Bhatt ID. Chromatographic and spectral fingerprinting standardization of traditional medicines: An overview as modern tools. Res. J. Phytochem, 2010; 4:234-241.

Gordon MH, Hudson JF. 1990. Food antioxidants. Elsevier Applied Science, London, 1-18

Grice HC. Safety evaluation of butylated hydroxytoluene (BHT) in the liver, lung and gastrointestinal tract. Food Chem. Toxicol, 1986; 24: $1127-1130$

Gulcin I. Antioxidant activity of caffeic acid (3,4dihydroxycinnamic acid). Toxicology,2006a; 217: 213.

Gulcin I. Antioxidant and antiradical activities of L-carnitine. Life Sciences, 2006b; 78: 803-811.

Gulcin I, Alici HA, Cesur M. Determination of in- vitro antioxidant and radical scavenging activities of propofol. Pharmacology Bulletin, 2005; 53:281-285.

Gulcin I, Buyukokuroglu ME, Oktay M, Kufrevioglu OI. On the in vitro antioxidant properties of melatonin. J. Pineal Res, 2002; 33:167-71.

Halliwell B. Reactive oxygen species in living systems: Source, biochemistry, and role in human disease. Am. J. Med, 1991; 91:14-22.

Hepsibha BT, Sathiya S, Babu CS, Premalakshmi V, Sekar T. In vitro studies of antioxidant and free radical scavenging activities of Azima tetracantha. Lam leaf extract. Indian J Sci Technol, 2010; 3:571577.

Hill AF. 1952. Economic Botany a Textbook of Useful Plants and Plant Products. 2nd Edn., McGarw-Hill Book Co. Inc, New York.

Hochestein P, Attalah AS. The nature of oxidant and antioxidant systems in the inhibition of mutation and cancer. Mutat. Res, 1988; 202: 363-375.

Huang DH, Chen C, Lin C, Lin Y. Antioxidant and antiproliferative activities of water spinach (Ipomoea aquatica Forsk.) constituents. Botanical Bulletin of Academic Science, 2005; 46:99-106.
Hung Y, Sava V, Yang SM, Hong MY, Yang PC, Huang GC. Isolation and characterization of melanin pigments derived from tea and tea polyphenols. Food Chem, 2001; 73: 177-184.

Ilhami GI, Haci AA, Mehmet C. Determination of in vitro antioxidant and radical Scavenging Activities of Propofol. Chem. Pharm. Bull, 2005; 53: 281-285.

George EI, Diejun C. Contents of phenolics and flavonoids and antioxidant activities in skin, pulp, and seeds of miracle fruit. Journal of Food Science, 2011; 76; 3.

Jayaprakasha GK, Sing RP, Sakariah KK. Antioxidant activity of grape seed (Vitrus vinifera) extracts on peroxidation models in vitro. Food Chem, 2001; 73: 285-290.

Jin M., Cai YX, Li JR, Zhao H. 1, 10-Phenanthroline-Fe ${ }^{2+}$ oxidative assay of hydroxyl radical produced by $\mathrm{H}_{2} \mathrm{O}_{2} / \mathrm{Fe}^{2+}$. Prog. Biochem. Biophys, 1996; 23: 553-555.

Johnston JW, Dussert S, Gale S, Nadarajan J, Harding K, Benson EE. Optimisation of the azinobis-3-ethyl-benzothiazoline6-sulphonic acid radical scavenging assay for physiological studies of total antioxidant activity in woody plant germplasm. Plant Physiol. Biochem, 2006; 44: 193-201.

Khilfi S, Hachimi E, Khalil A, Es-Safi A, Belahyam A, Tellal A, El Abbouyi A. In-vitro antioxidant properties of Salvia verbenaca. L. hydromethanolic extract. Indian Journal of Pharmacology, 2006; 38:276280 .

Kumaran A, Karunakaran RJ. Antioxidant and free radical scavenging activity of an aqueous extract of Coleus aromaticus. Food Chemistry, 2006; 97: 109-114.

Kumaran A, Karunakaran RJ. In vitro antioxidant activities of methanol extracts Offive Phyllanthus species from India. LWT - Food Sci. Technol, 2007; 40: 344-352.

Maritim AC, Sanders RA, Watkins JB. Diabetes, oxidative stress and antioxidants: a review. Journal of Biochemical and molecular Toxicology, 2003; 17:24-38

Minnoti G, Aust SD. An investigation into the mechanism of citrate $-\mathrm{Fe}^{2+}$ dependentlipid peroxidation .Free Rad Biol Med, 1987; 3: $379-387$.

Molyneux P. The use of stable free radical diphenylpicrylhydrazyl (DPPH) for estimating antioxidant activity. Songklanakarin $J$. Sci.and technol, 2004; 26:212-219.

Oyaizu M. Studies on product of browning reaction prepared from glucose amine. Jpn. J. Nutr, 1986; 44: 307-315.

Philips A, Philips S, Arul V, Padmakeerthiga B, Renju V, Santha $\mathrm{S}$ et al. Free radical scavenging activity of leaf extracts of Indigofera aspalathoides - An in vitro analysis. J Pharm Sci Res, 2010; 2:322-328.

Praveen A. Identifying and Quantifying Flavonoids in Three Medicinal Plants by HPLC. International Journal of Innovative Research and Development. 2012; 1: 344-362.

Prior RL, Wu X, Schaich K. Standardized methods for the determination of antioxidant capacity and phenolics in foods and dietary supplements. J. Agric. Food Chem, 2005;53: 4290-4302.

Rahila T, Rukhsandra N, Zaidi AA, Shamshila R. Phytochemical screening of medicinal plants belonging to family Euphorbiaceae. Pak. Vet. J, 1994; 14: 160-162.

Ramos, F, Takaishi Y, Kawazoe K, Osorio C, Duque C, Acuña $\mathrm{R}$, et al.Antioxidant activity applying an improved ABTS radical cation decolorization assay. Free Radic. Biol. Med, 1999;26: 1231-1237.

Ruberto G, Baratta MT. Antioxidant activity of selected essential oil components in two lipid model systems. FoodChemistry, 2000; 69:167-174.

Saumya SM, Mahaboob BP. In Vitro evaluation of free radical scavenging activities ofnPanax ginseng and Lagerstroemia speciosa: a comparative analysis. International Journal of Pharmacy and Pharmaceutical Sciences, 2011; 3:1

Sreejayan, Rao MN. Nitric oxide scavenging by curcuminoids. J. Pharm. Pharmacol, 1997; 49: 105-107

Sun J, Chen Y, Li M, Ge Z. Role of antioxidant enzymes on ionizing radiation resistance. Free Radical Biology and Medicine, 1998; 42:586-592. 
Terao J, Piscula M, Yao MC. Protective effect of epicatechin, epicatechin gallate and quercetin on lipid peroxidation in phoshpolipid bilayers. Archives of Biochemistry and Biophysics, 1994; 308:278-284.

Thirunavukkarasu P, Ramanathan T, Shanmugapriya R, Umamaheswari G, Renugadevi G. Antioxidant and free radical scavenging effect of Acanthus ilicifolius. Research Journal of Applied Sciences, 2011; 6: 218-222.

Tiwari, AK. Imbalance in antioxidant defence and human diseases: Multiple approach of natural antioxidant therapy. Curr. Sci. 2001; 81(9-10): 1179-1187.

Wichi HP. Enhanced tumor development by butylated hydroxyanisole (BHA) from the perspective of effect on the fore stomach and oesophageal squamous epithelium. Food Chem. Toxicol, 1988; 26: 717- 723.

World Health Organization. 1998. Regulatory situation of herbal medicine. A worldwide review. Geneva.

Yildrim A, Oktay M, Bilaloğlu V. The antioxidant activity of leaves of Cydonia $\quad$ vulgaris. Turkish Journal of Medical Science, 2001; 31:23-27.

\section{How to cite this article:}

Olabisi OT, Clement AA, Tolulope OM, Amos O, Kayode K, Olakunle AB, Akinwunmi AO, John FA, Aline BA, Linde AM.

High Performance Liquid Chromatography (HPLC) Fingerprinting, Mineral Composition and In Vitro Antioxidant Activity of Methanol Leaf Extract of Synsepalum dulcificum (Sapotaceae). J App Pharm Sci, 2017; 7 (11): 110-118. 